\title{
Patient selection and preoperative evaluation of percutaneous dilation tracheostomy in the intensive care unit
}

\author{
Mark Barash, Jonathan S. Kurman \\ Division of Pulmonary, Critical Care and Sleep Medicine, Medical College of Wisconsin, Milwaukee, WI, USA \\ Contributions: (I) Conception and design: Both authors; (II) Administrative support: None; (III) Provision of study materials or patients: None; (IV) \\ Collection and assembly of data: Both authors; (V) Data analysis and interpretation: Both authors; (VI) Manuscript writing: Both authors; (VII) Final \\ approval of manuscript: Both authors. \\ Correspondence to: Mark Barash, DO. Division of Pulmonary, Critical Care and Sleep Medicine, Hub for Collaborative Medicine, 8th Floor, 8701 \\ Watertown Plank Road, Milwaukee, WI 53226, USA. Email: mbarash@mcw.edu.
}

\begin{abstract}
Percutaneous dilation tracheostomy (PDT) is increasingly performed at the bedside of critically ill patients in the intensive care unit (ICU). PDT is safe overall and has a number of benefits compared to surgical tracheostomy. A tracheostomy tube has numerous advantages compared to an endotracheal tube, including decreased work of breathing, ease of connecting to a mechanical ventilator, improved patient comfort and pulmonary hygiene. Common patient populations include those unable to wean from mechanical ventilation, those requiring enhanced pulmonary hygiene, and those with progressive neuromuscular weakness. Clinicians performing this procedure should be familiar with common indications for performing tracheostomy as well as absolute and relative contraindications. Special patient populations, including those with morbid obesity, aberrant anatomic and vascular anatomy, cervical spine injury, and high ventilatory requirements, should be approached with careful planning. Pre-procedure evaluation for coagulopathy, including basic laboratory analysis and medication review, should be undertaken. Preprocedure ultrasound may be used to more accurately identify landmarks and vascular structures. The optimal timing for performing PDT is unknown and depends on the unique characteristics of each patient, perceived natural history of the disease process being addressed and open conversations with the patient or surrogate decision maker. In this review, we identify patient populations most likely to benefit from PDT and outline data behind optimal timing, pre-procedural laboratory evaluation and patient specific factors that may influence procedural success.
\end{abstract}

Keywords: Percutaneous dilation tracheostomy (PDT); patient selection; tracheostomy timing; intensive care unit (ICU)

Submitted Jul 20, 2020. Accepted for publication Nov 10, 2020.

doi: 10.21037/jtd-2019-ipicu-18

View this article at: http://dx.doi.org/10.21037/jtd-2019-ipicu-18

\section{Introduction}

Percutaneous dilation tracheostomy (PDT) is one of the most common bedside procedures performed in the intensive care unit (ICU), numbering greater than 110,000 per year in the United States (1) and can be performed by interventional pulmonologists and intensivists (2).

\section{Historical perspective}

In one form or another, tracheostomy has been described for millennia. Claudius Galen (131-201 AD) first described ventilating an animal by blowing air via a reed through its larynx (3). Alexander the Great (356-323 BC) reportedly used his sword to cut open the trachea of a soldier to 
Table 1 Examples of dimensions of three common tracheostomy tubes

\begin{tabular}{|c|c|c|c|c|c|c|c|c|}
\hline \multicolumn{3}{|c|}{ Bivona customized adjustable tracheostomy (SCT) } & \multicolumn{3}{|c|}{ Shiley (DIC) } & \multicolumn{3}{|c|}{ Shiley XLT (proximal or distal, DIC) } \\
\hline 6.0 & 8.7 & 67 & 5 & 9.4 & 62 & 5 & 9.6 & 90 \\
\hline 7.0 & 10.0 & 80 & 6.4 & 10.8 & 74 & 6 & 11.0 & 95 \\
\hline 8.0 & 11.0 & 89 & 7.6 & 12.2 & 79 & 7 & 12.3 & 100 \\
\hline 9.5 & 13.3 & 105 & & & & & & \\
\hline
\end{tabular}

SCT, single cannula tube; DIC, disposable inner cannula; XLT, extra-long tube, with either a proximal or distal length extension; I.D., inner diameter; O.D., outer diameter. Adapted from references $(7,8)$.

dislodge an aspirated bone (4). Almost 1,400 years after Galen, Andreas Vesalius (1514-1564) observed that ventilating an animal, which had sustained chest trauma, via a reed through the larynx prevented lung collapse when the chest wall was opened (3). In 1546, Antonio Brasavola performed the first documented successful tracheostomy on a patient with tonsillar obstruction (4). During the Danish polio outbreak of 1952, Bjørn Ibsen used positive pressure ventilation for patients with neuromuscular failure and set forth the modern era of mechanical ventilatory support (3). In 1955, PDT was introduced by Shelden et al. using the Seldinger technique (5).

Numerous refinements, modifications and tracheostomy kits have been created over the years, but the core concepts have remained unchanged. Clinicians performing PDT should have insight into which patients are most likely to benefit, the indications for performing PDT and how to evaluate a patient' for candidacy. In this review, we discuss factors clinicians ought to take into account when evaluating patients for PDT including patient characteristics, indications for PDT, anatomical considerations and timing. We also discuss pre-procedural considerations including comorbidities, laboratory analysis, the multidisciplinary approach and available literature to support these recommendations. Emergent PDT and/or cricothyrotomy are outside the scope of this narrative and not covered.

\section{Background}

A tracheostomy tube is a rigid, short $(\sim 60-105 \mathrm{~mm})$, curved cylindrical tube inserted through the trachea to maintain a patent airway when an endotracheal tube is either contraindicated, technically challenging to place or no longer satisfying its initial purpose. It is most commonly placed for continued ventilatory support. The inner diameter (I.D.) can range from $6.0-9.5 \mathrm{~mm}$, while the outer diameter (O.D.) ranges from 8.7 to $13.3 \mathrm{~mm}$ (6-8) (Table 1). Most commonly, in the non-emergent setting, it is inserted between the first and second or second and third tracheal rings (9) using some combination of an incision, blunt dissection and serial dilation via the modified Seldinger technique to enter the trachea. Its main components consist of an outer cannula which makes up the bulk of the visible tube and may have a distal inflatable cuff, a removable inner cannula and an obturator which aids in inserting the tracheostomy tube if it requires replacement. It can be made of a variety of materials, depending on the manufacturer and indication, including polyvinyl chloride (PVC), silicone, polyurethane and metal (6). Indications for PDT, which are discussed later, include difficulty weaning from mechanical ventilation, need for enhanced pulmonary hygiene, progressive neuromuscular weakness and upper airway obstruction from tumors, maxillofacial trauma, laryngeal edema and other benign causes.

Compared to an endotracheal tube, a tracheostomy tube has several theoretical advantages. First, its shorter length and potentially larger I.D., as compared to an adult endotracheal tube, reduces resistance to airflow, as resistance is directly proportional to length and inversely proportional to radius to the fourth power. To a critically ill patient with deconditioning and neuromuscular weakness in the ICU, a decrease in work of breathing may accompany placement of a tracheostomy tube (10). It is possible that the rigid design, as compared to a thermolabile endotracheal tube, may contribute to a tendency to maintain a more constant I.D. and decrease turbulent airflow (11). By manipulating the properties of the tube, patients may benefit from a decrease in inspiratory resistive work of breathing, intrinsic positive 
Table 2 Absolute and relative contraindications to percutaneous dilational tracheostomy

\begin{tabular}{ll}
\hline Absolute & Relative \\
\hline Infection at insertion site & $\begin{array}{l}\text { Anatomic or vascular abnormalities of } \\
\text { the neck }\end{array}$ \\
Operator inexperience & Coagulopathy \\
& Clinical instability (hemodynamic or \\
& respiratory) \\
& High ventilator/positive end-expiratory \\
& pressure (PEEP) requirements \\
& Maxillofacial trauma \\
& Obesity/large neck size \\
& Prior tracheostomy \\
& Recent neck/cervical spine surgery \\
&
\end{tabular}

end-expiratory pressure (PEEP) and resistive and elastic work of breathing (12). When comparing work of breathing in anesthetized patients, a $6.0 \mathrm{~mm}$ I.D. tube, as compared to a $9.0 \mathrm{~mm}$ I.D. tube increased the work of breathing by up to $490 \%$ (13).

PDT simplifies suctioning and pulmonary hygiene (14). Patients benefit from a removable and replaceable inner cannula, which allows for easier cleaning of airway and tracheostomy debris and preserves the integrity of the outer cannula. Because a tracheostomy tube can be easily connected and disconnected from a ventilator, clinicians can be more aggressive with weaning trials. This is in contrast to an endotracheal tube, which would require sedation and possible paralysis to re-insert, increasing the likelihood of peri-procedural complications.

Patients may also benefit from enhanced quality of life. By freeing the supra-laryngeal structures from the space occupying effects of an endotracheal tube, PDT may allow patients to increase oral intake and speak via a PassyMuir valve (or other available speaking valves) by forcing air cephalad past the tracheostomy and through the vocal cords (15). A more secure and less cumbersome airway also improves patients' abilities to work with physical therapy and increases mobility (14).

\section{Patient selection}

The most common indication for PDT is prolonged mechanical ventilation (16). Patient populations include those with severe pulmonary infections, acquired neuromuscular weakness from prolonged critical illness, those with progressive neuromuscular disorders such as amyotrophic lateral sclerosis (ALS), and severe obstructive sleep apnea with recurrent respiratory failure recalcitrant to standard therapy.

Indications for PDT generally include to (I) facilitate weaning from mechanical ventilation, (II) improve patient comfort and facilitate physical rehabilitation and (III) provide a conduit for enhanced mucous clearance and pulmonary toilet (17).

\section{Absolute and relative contraindications}

PDT is a safe and well tolerated procedure. Complications are relatively rare and can be grouped into intraoperative, early ( $<1$ week) and late. These include bleeding, soft tissue infection, laceration of the posterior tracheal wall, tracheoesophageal stricture, and tracheal stenosis, among others (18). Very few absolute contraindications exist and mainly include superficial or deep soft tissue infection at the site of insertion and operator inexperience (9). Relative contraindications are more numerous and are at the discretion of the proceduralist. These include coagulopathy, anatomic considerations (i.e., large or short neck, maxillofacial trauma, cervical spine instability), clinical or hemodynamic instability and high ventilator requirements [high PEEP or fractional inspired oxygen $\left(\mathrm{FiO}_{2}\right)$ ] (Table 2) (9). A holistic approach should be taken with patients unlikely to achieve an improvement in quality of life or survive the procedure, particularly if on a comfort plan of care or transitioning to hospice. All patients should be counselled on the risks and benefits of the procedure. In situations where competing interests between patient, physician and family members intersect and the benefit of PDT is not clear, consultation with an ethics committee may be warranted (19).

\section{Anatomical considerations}

The tracheostomy tube is generally inserted between the second and third or first and second tracheal rings. Ideally, landmarks such as the thyroid cartilage, cricothyroid membrane, tracheal rings and sternal notch should be easily identified and marked. Critically ill patients represent a heterogenous cohort with complex medical issues. As the obesity epidemic increases, the proceduralist is more likely to encounter larger neck sizes that may make identifying key landmarks more challenging. Several authors have 
studied safety outcomes of obese patients undergoing PDT. Mansharamani et al. performed a retrospective analysis of thirteen consecutive patients undergoing bedside PDT with $\mathrm{BMI} \geq 27 \mathrm{~kg} / \mathrm{m}^{2}$. Patients had a mean BMI of $45.9 \pm$ $12.4 \mathrm{~kg} / \mathrm{m}^{2}$ and procedural complications were limited to one case of paratracheal tracheostomy placement which was immediately identified and corrected (20). In another retrospective review of 89 obese patients (BMI $\geq 35 \mathrm{~kg} / \mathrm{m}^{2}$ ) undergoing tracheostomy there was no difference in primary endpoints including tracheostomy malpositioning, loss of airway control and bleeding requiring surgical intervention as compared to those who underwent surgical tracheostomy (21).

Special care should be taken with patients with cervical spine trauma or recent surgery as traditionally the neck is extended during PDT. However, PDT appears to be safe without neck extension. In a case series of 88 consecutive cervical spine trauma patients, there was no difference in rates of complications between the "cleared" and "noncleared" patients and no instances of spinal cord injury from the tracheostomy procedure itself. Twenty-seven of 28 in the non-cleared group were maintained in a neutral position without extension (22).

Prior tracheostomy has, anecdotally, been viewed as a relative contraindication to repeat PDT owing to the presence of scar tissue and possibly altered anatomy. In a retrospective review of repeat bedside PDT, Meyer et al. found no increase in periprocedural complications or surgical revision (23). Yilmaz et al. prospectively enrolled 12 consecutive critically ill patients with prior tracheostomy to undergo PDT. They reported no significant complications, no patients required conversion to surgical tracheostomy and three patients underwent pre-procedural ultrasound guided needle aspiration to identify the trachea (24). In addition, a residual tracheostomy scar may help identify landmarks in those with large necks or ambiguous external anatomy.

Other anatomical considerations should include the ease by which an endotracheal tube can be replaced if it were to be dislodged in the periprocedural period prior to an established airway with a tracheostomy tube. Patients with laryngeal edema, vocal cord paralysis, subglottic stenosis and maxillofacial trauma should be approached with care in this regard, and proper planning, equipment and staff should be available in the event that the airway is lost and cannot be easily re-established before the tracheostomy tube is inserted and secured.

\section{High ventilatory settings}

In a study of 198 consecutive patients undergoing PDT, patients were stratified into high PEEP ( $>10 \mathrm{mbar}, \mathrm{n}=88$ ) or low PEEP ( $\leq 10$ mbar, $n=115)$. The average end-expiratory pressure was $16.6 \pm 4$ mbar in the high PEEP group, and $7.6 \pm 2.2$ mbar in the low PEEP group. No significant decrease in oxygenation was noted in either group at 1 and 24 hours after PDT, nor was there significant deterioration in oxygenation in patients with the lowest quartile of preprocedure ratio of arterial partial pressure of oxygen $\left(\mathrm{PaO}_{2}\right)$ to $\mathrm{FiO}_{2}$ content (25).

\section{Aspiration}

It may be convenient to assume that the presence of an inflatable cuff at the distal end of the tracheostomy leads to decreased aspiration. Unfortunately, this is not supported by the literature. The cuff sits at the distal end of the tracheostomy tube which places it somewhere in the mid $1 / 3$ of the trachea and does not prevent the reflux of gastric or oral contents through the vocal cords which are located superiorly. Since the balloon is generally inflated to 20 to $25 \mathrm{mmHg}$ (to avoid tracheal ischemia) (14) it cannot adequately prevent pooled secretions at its superior interface from eventually leaking past its lateral wall and down the tracheobronchial tree. In one study of 52 patients, $33 \%$ were noted to have macro-aspiration (food particles visible below the true vocal cords) and $82 \%$ of that group were considered silent aspirators (26). Another study of 83 patients on chronic mechanical ventilation noted that $50 \%$ aspirated on video-fluoroscopy and $77 \%$ of those were silent aspirations (27). When dye was applied to the tongue of patients with tracheostomy, $69 \%$ of patients had dye visualized upon suctioning within 30 hours (28). Therefore, patients should be counselled that the addition of a cuffed tracheostomy tube will not prevent future episodes of aspiration.

\section{Timing of tracheostomy: early versus late}

No consensus exists regarding optimal timing for PDT. This question is complicated by the lack of clarity and significant heterogeneity in the definition of the terms 'early' and 'late' in the timing of tracheostomy from the first day of endotracheal intubation. To date, only one randomized controlled trial (RCT) (29) and one meta-analysis (30) have shown mortality benefit in early PDT as compared to late 
Table 3 Major outcomes of selected recent RCTs and meta-analyses comparing "early" and "late" PDT

\begin{tabular}{|c|c|c|c|c|c|c|c|}
\hline Outcomes & Mortality & $\begin{array}{l}\text { ICU length of } \\
\text { stay }\end{array}$ & $\begin{array}{l}\text { Duration of } \\
\text { mechanical } \\
\text { ventilation }\end{array}$ & $\begin{array}{l}\text { Ventilator } \\
\text { associated } \\
\text { pneumonia }\end{array}$ & $\begin{array}{c}\text { Duration of } \\
\text { sedation }\end{array}$ & $\begin{array}{c}\text { Etiology of } \\
\text { critical illness }\end{array}$ & $\begin{array}{c}\text { Procedural } \\
\text { complications }\end{array}$ \\
\hline Rumbak et al. 2004 (29) & Early & Early & Early & $x$ & $x$ & $x$ & $x$ \\
\hline Terragni et al. 2010 (31) & None & None & None & $x$ & $x$ & $x$ & $x$ \\
\hline \multicolumn{8}{|l|}{ Meta-analysis } \\
\hline Griffiths et al. 2005 (33) & None & Early & Early & $x$ & $x$ & $x$ & $x$ \\
\hline Andriolo et al. 2015 (30) & Early & Early & $x$ & None & $x$ & $x$ & $x$ \\
\hline Siempos et al. 2015 (34) & None & $x$ & $x$ & None & $x$ & $x$ & $x$ \\
\hline
\end{tabular}

None: no benefit was identified; Early: early PDT group showed benefit; X: not evaluated. RCT, randomized controlled trial; PDT, percutaneous dilation tracheostomy; ICU, intensive care unit.

PDT. Data on ICU length of stay, ventilator free days, prevention of ventilator associated pneumonia and other complications remains heterogenous (Table 3).

Mortality benefit of early tracheostomy (within 48 hours vs. 14-16 days) was demonstrated on a prospective RCT of 100 patients in a medical ICU. Compared to delayed PDT, early PDT was associated with reduced mortality $(31.7 \%$ $v s .61 .7 \%)$, decreased ICU length of stay $(4.8 \pm 1.4 v s .16 .2 \pm$ 3.8 days) and decreased days on mechanical ventilation (7.6 \pm 2.0 vs. $17.4 \pm 5.3$ days) (29). At the time of this writing, this is the only known RCT that has demonstrated mortality benefit. In an RCT of 419 patients, Terragni et al. demonstrated no difference between early (6-8 days) and late (13-15 days) PDT in terms of ventilator associated pneumonia, time to ventilator independence, remaining in the ICU and mortality (31). In another multicenter RCT, Young et al. randomized 909 patients into early (4 days) and late (10 days) PDT groups; there was no statistically significant reduction in all-cause mortality at 30 days or 2 years, ICU length of stay, or complications. In addition, of the early group, $91.9 \%$ received tracheostomy, while only $44.9 \%$ of the late group received tracheostomy (32). This observation likely indicates that a number of the early tracheostomy cohort may have been successfully extubated had the natural history of their disease process simply run its course, obviating the need for tracheostomy in the first place.
In a 2005 meta-analysis of 12 randomized or quasirandomized trials of 406 participants, early tracheostomy did not result in improved mortality but did reduce duration of mechanical ventilation and length of stay in the ICU (33). A meta-analysis of 16 trials encompassing 2,434 patients found no significant reduction in all-cause mortality. The incidence of ventilator-associated pneumonia did appear to be lower in patients undergoing early tracheostomy. Of the 16 trials, early tracheostomy was defined as being performed between $\leq 2$ to 8 days from endotracheal intubation, while late tracheostomy was defined as being performed between $\geq 6$ to $\geq 29$ days with significant heterogeneity in the interstudy definitions (34). Andriolo et al. evaluated eight RCTs with 1,977 participants and demonstrated a mortality benefit [risk ratio (RR): $0.83,95 \% \mathrm{CI}: 0.7$ to $0.98 ; \mathrm{P}=0.03$ ] with a higher likelihood of discharge from the ICU at 28 days (RR: $1.29,95 \%$ CI: 1.08 to 1.55 ; $\mathrm{P}=0.06$ ) (30). Another meta-analysis of 11 studies did demonstrate a significant decrease in ICU length of stay in the early (within 7 days) tracheostomy group (weighted mean difference, -9.13 days; $95 \%$ confidence interval -17.55 to $0.70 ; \mathrm{P}=0.03$ ) as compared to late tracheostomy although no mortality benefit was found. A sub-group analysis also failed to show a difference in outcomes based on the etiology of critical illness (35). Meng et al. performed a meta-analysis on 9 studies with a total of 2,040 patients and defined early tracheostomy as $\leq 10$ days since endotracheal intubation and 
late tracheostomy as >10 days since endotracheal intubation. They noted a reduction in duration of sedation in the early tracheostomy group (weighted mean difference, -5.99 days, $95 \%$ confidence interval -11.41 to 0.57 days; $\mathrm{P}=0.03$ ) but no significant effect on mortality, incidence of ventilator associated mortality, duration of mechanical ventilation and ICU length of stay (36).

Patients with acute, severe cervical spine injuryparticularly those with high cervical level (above C-4) and when the motor grade of the American Spinal Injury Association (ASIA) is low-may be considered for early tracheostomy (37). A retrospective analysis of 156 patients showed that all patients with C-2/3 ASIA grade A injuries underwent tracheostomy, and patients older than 45 years of age with ASIA grade A levels between C-4 and C-7 more commonly required a tracheostomy (38).

The decision to perform PDT should first be based on adequate patient selection, agreement from the patient or the designated decision maker and the weight of benefit over harm. Once established, the clinician should have a sense of the natural history of the disease being addressed. Therefore, the decision to pursue early or late PDT remains at the discretion of clinician equipoise but at present, there does not appear to be convincing data demonstrating benefit of one over the other.

\section{Pre-procedural evaluation}

\section{Evaluation for coagulopathy}

Patients undergoing PDT require routine laboratory evaluation with special attention to platelet count, markers of coagulopathy [prothrombin time, international normalized ratio (INR) and partial thromboplastin time], liver function testing and creatinine ('uremic platelets').

In a retrospective review of 1,001 consecutive patients undergoing PDT, Pilarczyk et al. identified three coagulative states that increased risk for moderate, severe or major bleeding. These included (I) platelet count $<80 \times 10^{9} / \mathrm{L}$ (57.9\% vs. 41.4\%, P=0.007); (II) fibrinogen $<7.4 \mu \mathrm{mol} / \mathrm{L}$ (30.7\% vs. $18.7 \%, \mathrm{P}=0.022)$ and; (III) coagulopathy $(54.5 \%$ vs. $43.0 \%, \mathrm{P}=0.043)$ defined as one or more of a composite of (i) platelets $<50 \times 10^{9} / \mathrm{L}$, (ii) prothrombin time $>50 \%$ of normal reference value and/or (iii) activated partial thromboplastin time $>50 \mathrm{~s}$. Patient factors included need for renal replacement therapy $(60.2 \%$ vs. $48.1 \%, \mathrm{P}=0.026)$ and a simplified acute physiology score (SAPS) $>40(68.2 \%$ vs. $25.2 \%, \mathrm{P}<0.001)$. Other factors that increased the risk for significant bleeding included PDT performed by a resident (81.8\% vs. 69.2\%, $\mathrm{P}=0.034)$. Interestingly, after multivariate analysis, only low fibrinogen levels retained significance as a predictor of bleeding. There were no recorded deaths or major complications including cardiac arrest, hypoxemia, accidental extubation or pneumothorax (39). In a smaller retrospective study of 415 patients undergoing PDT, only Beiderlinden et al. noted that increased risk of chronic bleeding (stomal bleeding for $>24$ hours after placement of tracheostomy) was associated with (I) platelet count $<50 \times 10^{9} / \mathrm{L}(\mathrm{OR}: 5.0$, 95\% CI: 1.4-17.2); (II) an activated partial thromboplastin time >50 s (OR: 3.7, 95\% CI: 1.1-12.7) and; (III) two or more abnormal coagulation variables (OR: 9.5, $95 \%$ CI: 2.3-34.7). Use of low dose heparin did not increase the risk of bleeding. Only two major bleeding episodes required surgical intervention, and all other episodes were controlled with combinations of bronchoscopy, suturing or electrocoagulation (40). Deppe et al. performed a retrospective single-center cohort study on 220 patients undergoing PDT. Patients were grouped into low and high-risk groups based on activated partial thromboplastin time $>50 \mathrm{~s}$, prothrombin time $>50 \%$, INR $>1.4$ and platelet count $<50 \times 10^{9} / \mathrm{L}$. Both groups showed statistically insignificant differences $(\mathrm{P}=0.957)$ in mild bleeding with no cases of severe bleeding, complications or need for surgical intervention (41).

\section{Liver dysfunction}

Patients with liver dysfunction or liver failure suffer from dysregulated coagulation cascades. In a prospective cohort study (42), 25 patients with liver disease underwent PDT and had refractory coagulopathy (platelet count $<50 \times 10^{9} / \mathrm{L}$ or INR $>1.5$ ) on the day of and 72 hours post-operatively. Only 1 patient had significant bleeding but did not require surgical intervention, and there was no increase in hospital mortality. Over 3 days post-PDT, patients with refractory coagulopathy received more platelets. PDT is likely safe in patients with severe liver disease, but caution should be exercised even by experienced operators.

\section{Platelet dysfunction}

In general, a platelet count of $>50,000$ is considered safe for performing PDT.

In a retrospective review of 20 patients on clopidogrel at the time of PDT (compared to a control group of 137 
patients), no major bleeding events occurred, while minor bleeding occurred in $5 \%$ of the clopidogrel group, and in $3.6 \%$ of the control group $(\mathrm{P}=0.85)$ (43). In another retrospective analysis of 15 patients on dual antiplatelet therapy (clopidogrel and aspirin), there were no major bleeding events. Three patients in the dual-therapy group and five patients in the control group $(\mathrm{N}=41)$ required interventions to control bleeding, such as application of prolonged pressure or topical epinephrine (44). Dual antiplatelet therapy did not increase the risk of bleeding in another retrospective study of 1,001 patients undergoing PDT (39).

\section{Renal function}

No guidelines exist on routine assessment of creatinine and blood urea nitrogen (BUN). It is well recognized that chronic kidney disease leads to platelet dysfunction, sometimes referred to as "uremic platelets", postulated to be caused by a lack of platelet aggregation and abnormal platelet-endothelial interactions (45). Dysfunction of glycoprotein IIb/IIIa and its ability to interact with fibrinogen and von Willebrand factor plays a role (46). Desmopressin (DDAVP) exerts the effect of increasing endothelial release of factor VIII: von Willebrand multimers and improves platelet function in vitro (47). While an attractive adjunct to activate uremic platelets, there is a paucity of literature that demonstrates increased risk of bleeding in patients with renal dysfunction. The authors do not recommend for or against routine assessment of renal function or use of DDAVP in PDT.

\section{Consideration for surgical tracheostomy}

Certain scenarios may warrant consideration of surgical tracheostomy. As compared to surgical tracheostomy, PDT benefits from a lower incidence of wound infections and scarring, while there is no significant difference in the incidence of false passage, minor or major hemorrhage or subglottic stenosis. In addition, PDT may lead to a decrease in procedural time and a reduction in expenses (48). PDT can also be performed by a broader range of physicians, particularly those in non-surgical specialties, with no increase in complications (49). Nonetheless, certain patient populations-obesity with indistinguishable landmarks, maxillofacial trauma, unstable cervical spine fracture, those with aberrant vascular anatomy, extrinsic tracheal compression from mediastinal mass or tracheal obstruction from intrinsic tumor or stenosis near or below the site of tracheostomy_are more suitable for a surgical tracheostomy.

\section{Use of ultrasound}

Pre-operative use of ultrasound is a safe and non-invasive method to identify landmarks and vasculature prior to performing PDT (50). A linear probe is usually sufficient. Easily identifiable structures include tracheal midline, thyroid isthmus, anterior jugular vein (51), tracheal rings, and pre-tracheal vessels overlying the PDT site (52). Use of color doppler, presence of vascular pulsatility or compressibility allow for easy discrimination between veins and arteries. A small prospective study comparing use of ultrasound in obese (median BMI $34 \mathrm{~kg} / \mathrm{m}^{2}$ ) and nonobese (median BMI $25 \mathrm{~kg} / \mathrm{m}^{2}$ ) patients undergoing PDT demonstrated no difference in minor complication rates ( $35 \%$ vs. $33 \%, \mathrm{P}=0.92$ ), and the use of ultrasound led to a change in puncture site in $50 \%$ of cases due to identification of vascular or other tissue anomalies (53). Based on these data, we recommend routine pre-procedural ultrasound assessment prior to planned PDT if possible. An indepth review on use of ultrasound to identify anatomical landmarks is beyond the scope of this manuscript but has been previously published (54).

\section{Other imaging modalities}

If available, previous computed tomography (CT) imaging of the chest or neck can be utilized for planning purposes. Utilizing three planes of image acquisition, the proceduralist can easily identify anatomic variants such as an enlarged thyroid gland, aberrant vascular structures or the relative position of the tracheal structures relative to the bony landmarks of the upper chest. No data exist on improved outcomes with PDT, and the authors do not recommend obtaining dedicated imaging prior to the procedure.

\section{Clinician competence and multidisciplinary approach}

As with all procedures, a learning curve exists toward competence in performing PDT. Proficiency is directly correlated with the number of procedures performed (18), and simulation training on animals or mannequins may improve procedural competence and retention (55). Perioperative complications seem to decrease after a 
threshold of about 20 PDTs (56), although the number to achieve competency is unknown and likely higher, particularly when related to complex cases. The American College of Chest physicians recommends at least 20 PDTs in a supervised setting to establish basic competency and at least ten procedures yearly to maintain proficiency (57).

A multidisciplinary approach toward initiating PDT should be encouraged and has been shown to improve outcomes and decrease complication rates (58). A clear plan should be outlined, and the clinician should solicit feedback from team members including nursing staff, respiratory therapist, patient care technicians/nursing aids, other physicians, learners and trainees participating in the procedure. Speech-language pathologists and case managers are vital for coordination of post-tracheostomy care and eventual disposition to home or other care facilities. The proceduralist and those taking care of the patient with a tracheostomy should be trained in routine and emergent management of tracheostomy complications; those without expertise should know who to contact if issues arise (59).

\section{Conclusions}

PDT is increasingly performed at the bedside by a variety of surgical and non-surgically trained clinicians. A clear understanding of indications, relative and absolute contraindications, and patient selection criteria is necessary for those performing this procedure.

\section{Acknowledgments}

Funding: None.

\section{Footnote}

Provenance and Peer Review: This article was commissioned by the editorial office, Fournal of Thoracic Disease for the series "Interventional Pulmonology in the Intensive Care Unit Environment". The article has undergone external peer review.

Conflicts of Interest: Both authors have completed the ICMJE uniform disclosure form (available at http://dx.doi. org/10.21037/jtd-2019-ipicu-18). The series "Interventional Pulmonology in the Intensive Care Unit Environment" was commissioned by the editorial office without any funding sponsorship. JSK served as the unpaid Guest Editor of the series. Dr. JSK reports personal fees from Level
Ex, personal fees from Medtronic, other from Pinnacle Biologics, personal fees from Biodesix, personal fees from American Medical Forum, outside the submitted work. The authors have no other conflicts of interest to declare.

Ethical Statement: The authors are accountable for all aspects of the work in ensuring that questions related to the accuracy or integrity of any part of the work are appropriately investigated and resolved.

Open Access Statement: This is an Open Access article distributed in accordance with the Creative Commons Attribution-NonCommercial-NoDerivs 4.0 International License (CC BY-NC-ND 4.0), which permits the noncommercial replication and distribution of the article with the strict proviso that no changes or edits are made and the original work is properly cited (including links to both the formal publication through the relevant DOI and the license). See: https://creativecommons.org/licenses/by-nc-nd/4.0/.

\section{References}

1. Shah RK, Lander L, Berry JG, et al. Tracheotomy outcomes and complications: a national perspective. Laryngoscope 2012;122:25-9.

2. Wahidi MM, Herth FJF, Chen A, et al. State of the art: interventional pulmonology. Chest 2020;157:724-36.

3. Bolton CF, Chen R, Wijdicks EFM, et al. Neurology of breathing. Philadelphia: Elsevier, 1994.

4. Szmuk P, Ezri T, Evron S, et al. A brief history of tracheostomy and tracheal intubation, from the Bronze Age to the Space Age. Intensive Care Med 2008;34:222-8.

5. Shelden CH, Pudenz RH, Freshwater DB, et al. A new method for tracheotomy. J Neurosurg 1955;12:428-31.

6. Hess DR, Altobelli NP. Tracheostomy tubes. Respir Care 2014;59:956-71; discussion 971-3.

7. Medtronic. Medtronic tracheostomy products. Available online: https://www.medtronic.com/covidien/en-us/ products/tracheostomy.html (Accessed July 1, 2020).

8. Smiths Medical Products: Tracheostomy Products Available online: https://www.smiths-medical.com/en-us/ products/tracheostomy (Accessed July 1, 2020).

9. Rashid AO, Islam S. Percutaneous tracheostomy: a comprehensive review. J Thorac Dis 2017;9:S1128-38.

10. Diehl JL, El Atrous S, Touchard D, et al. Changes in the work of breathing induced by tracheotomy in ventilator-dependent patients. Am J Respir Crit Care Med 1999;159:383-8. 
11. Davis K Jr, Campbell RS, Johannigman JA, et al. Changes in respiratory mechanics after tracheostomy. Arch Surg 1999;134:59-62.

12. Moscovici da Cruz V, Demarzo SE, Sobrinho JB, et al. Effects of tracheotomy on respiratory mechanics in spontaneously breathing patients. Eur Respir J 2002;20:112-7.

13. Bersten AD, Rutten AJ, Vedig AE, et al. Additional work of breathing imposed by endotracheal tubes, breathing circuits, and intensive care ventilators. Crit Care Med 1989;17:671-7.

14. Heffner JE, Hess D. Tracheostomy management in the chronically ventilated patient. Clin Chest Med 2001;22:55-69.

15. Passy V, Baydur A, Prentice W, et al. Passy-Muir tracheostomy speaking valve on ventilator-dependent patients. Laryngoscope 1993;103:653-8.

16. Freeman BD. Tracheostomy Update: When and How. Crit Care Clin 2017;33:311-22.

17. Mehta C, Mehta Y. Percutaneous tracheostomy. Ann Card Anaesth 2017;20:S19-25.

18. Halum SL, Ting JY, Plowman EK, et al. A multiinstitutional analysis of tracheotomy complications. Laryngoscope 2012;122:38-45.

19. Venkat A. The threshold moment: ethical tensions surrounding decision making on tracheostomy for patients in the intensive care unit. J Clin Ethics 2013;24:135-43.

20. Mansharamani NG, Koziel H, Garland R, et al. Safety of bedside percutaneous dilatational tracheostomy in obese patients in the ICU. Chest 2000;117:1426-9.

21. Heyrosa MG, Melniczek DM, Rovito P, et al. Percutaneous tracheostomy: a safe procedure in the morbidly obese. J Am Coll Surg 2006;202:618-22.

22. Mayberry JC, Wu IC, Goldman RK, et al. Cervical spine clearance and neck extension during percutaneous tracheostomy in trauma patients. Crit Care Med 2000;28:3436-40.

23. Meyer M, Critchlow J, Mansharamani N, et al. Repeat bedside percutaneous dilational tracheostomy is a safe procedure. Crit Care Med 2002;30:986-8.

24. Yilmaz M, Dosemeci L, Cengiz M, et al. Repeat percutaneous tracheostomy in the neurocritically ill patient. Neurocrit Care 2006;5:120-3.

25. Beiderlinden M, Groeben H, Peters J. Safety of percutaneous dilational tracheostomy in patients ventilated with high positive end-expiratory pressure (PEEP). Intensive Care Med 2003;29:944-8.

26. Leder SB. Incidence and type of aspiration in acute care patients requiring mechanical ventilation via a new tracheotomy. Chest 2002;122:1721-6.

27. Elpern EH, Scott MG, Petro L, et al. Pulmonary aspiration in mechanically ventilated patients with tracheostomies. Chest 1994;105:563-6.

28. Cameron JL, Reynolds J, Zuidema GD. Aspiration in patients with tracheostomies. Surg Gynecol Obstet 1973;136:68-70.

29. Rumbak MJ, Newton M, Truncale T, et al. A prospective, randomized, study comparing early percutaneous dilational tracheotomy to prolonged translaryngeal intubation (delayed tracheotomy) in critically ill medical patients. Crit Care Med 2004;32:1689-94.

30. Andriolo BN, Andriolo RB, Saconato H, et al. Early versus late tracheostomy for critically ill patients. Cochrane Database Syst Rev 2015;1:CD007271.

31. Terragni PP, Antonelli M, Fumagalli R, et al. Early vs late tracheotomy for prevention of pneumonia in mechanically ventilated adult ICU patients: a randomized controlled trial. JAMA 2010;303:1483-9.

32. Young D, Harrison DA, Cuthbertson BH, et al. Effect of early vs late tracheostomy placement on survival in patients receiving mechanical ventilation: the TracMan randomized trial. JAMA 2013;309:2121-9.

33. Griffiths J, Barber VS, Morgan L, et al. Systematic review and meta-analysis of studies of the timing of tracheostomy in adult patients undergoing artificial ventilation. BMJ 2005;330:1243.

34. Siempos II, Ntaidou TK, Filippidis FT, et al. Effect of early versus late or no tracheostomy on mortality and pneumonia of critically ill patients receiving mechanical ventilation: a systematic review and meta-analysis. Lancet Respir Med 2015;3:150-8.

35. Liu CC, Livingstone D, Dixon E, et al. Early versus late tracheostomy: a systematic review and meta-analysis. Otolaryngol Head Neck Surg 2015;152:219-27.

36. Meng L, Wang C, Li J, et al. Early vs late tracheostomy in critically ill patients: a systematic review and meta-analysis. Clin Respir J 2016;10:684-92.

37. Beom JY, Seo HY. The need for early tracheostomy in patients with traumatic cervical cord injury. Clin Orthop Surg 2018;10:191-6.

38. Harrop JS, Sharan AD, Scheid EH Jr, et al. Tracheostomy placement in patients with complete cervical spinal cord injuries: American Spinal Injury Association Grade A. J Neurosurg 2004;100:20-3.

39. Pilarczyk K, Haake N, Dudasova M, et al. Risk factors for bleeding complications after percutaneous dilatational 
tracheostomy: a ten-year institutional analysis. Anaesth Intensive Care 2016;44:227-36.

40. Beiderlinden M, Eikermann M, Lehmann N, et al. Risk factors associated with bleeding during and after percutaneous dilational tracheostomy. Anaesthesia 2007;62:342-6.

41. Deppe AC, Kuhn E, Scherner M, et al. Coagulation disorders do not increase the risk for bleeding during percutaneous dilatational tracheotomy. Thorac Cardiovasc Surg 2013;61:234-9.

42. Auzinger G, O'Callaghan GP, Bernal W, et al. Percutaneous tracheostomy in patients with severe liver disease and a high incidence of refractory coagulopathy: a prospective trial. Crit Care 2007;11:R110.

43. Abouzgheib W, Meena N, Jagtap P, et al. Percutaneous dilational tracheostomy in patients receiving antiplatelet therapy: is it safe? J Bronchology Interv Pulmonol 2013;20:322-5.

44. Voigt I, Naber C. Bleeding complications of percutaneous dilatation tracheostomy (PDT) in a group of ICU patients with dual antiplatelet therapy. Crit Care Shock 2012;15:70-6.

45. Weigert AL, Schafer AI. Uremic bleeding: pathogenesis and therapy. Am J Med Sci 1998;316:94-104.

46. Escolar G, Cases A, Bastida E, et al. Uremic platelets have a functional defect affecting the interaction of von Willebrand factor with glycoprotein IIb-IIIa. Blood 1990;76:1336-40.

47. Zeigler ZR, Megaludis A, Fraley DS. Desmopressin (d-DAVP) effects on platelet rheology and von Willebrand factor activities in uremia. Am J Hematol 1992;39:90-5.

48. Higgins KM, Punthakee X. Meta-analysis comparison of open versus percutaneous tracheostomy. Laryngoscope 2007;117:447-54.

49. Yarmus L, Pandian V, Gilbert C, et al. Safety and efficiency of interventional pulmonologists performing percutaneous tracheostomy. Respiration 2012;84:123-7.

50. Flint AC, Midde R, Rao VA, et al. Bedside ultrasound screening for pretracheal vascular structures may minimize the risks of percutaneous dilatational tracheostomy. Neurocrit Care 2009;11:372-6.

51. Hatfield A, Bodenham A. Portable ultrasonic scanning of the anterior neck before percutaneous dilatational tracheostomy. Anaesthesia 1999;54:660-3.

52. Rees J, Haroon Y, Hogan C, et al. The ultrasound neck imaging for tracheostomy study: a study prompting ultrasound screening prior to percutaneous tracheostomy procedures to improve patient outcomes. J Intensive Care Soc 2018;19:107-13.

53. Guinot PG, Zogheib E, Petiot S, et al. Ultrasound-guided percutaneous tracheostomy in critically ill obese patients. Crit Care 2012;16:R40.

54. Alansari M, Alotair H, Al Aseri Z, et al. Use of ultrasound guidance to improve the safety of percutaneous dilatational tracheostomy: a literature review. Crit Care 2015;19:229.

55. Custalow CB, Kline JA, Marx JA, et al. Emergency department resuscitative procedures: animal laboratory training improves procedural competency and speed. Acad Emerg Med 2002;9:575-86.

56. Massick DD, Powell DM, Price PD, et al. Quantification of the learning curve for percutaneous dilatational tracheotomy. Laryngoscope 2000;110:222-8.

57. Ernst A, Silvestri GA, Johnstone D. Interventional pulmonary procedures: Guidelines from the American College of Chest Physicians. Chest 2003;123:1693-717.

58. Pandian V, Miller CR, Mirski MA, et al. Multidisciplinary team approach in the management of tracheostomy patients. Otolaryngol Head Neck Surg 2012;147:684-91.

59. Black E, Allan R. Medical High Dependency Unit series, Article 4: Tracheostomy management. Acute Med 2017;16:185-91.
Cite this article as: Barash M, Kurman JS. Patient selection and preoperative evaluation of percutaneous dilation tracheostomy in the intensive care unit. J Thorac Dis 2021;13(8):5251-5260. doi: 10.21037/jtd-2019-ipicu-18 